\title{
Chronic kidney disease in the $B C R$-ABLI-negative myeloproliferative neoplasm: a single-center retrospective study
}

Seung-Woo Baek, Ji Young Moon, Hyewon Ryu, Yoon-Seok Choi, Ik-Chan Song, Hyo-Jin Lee, Hwan-Jung Yun, Samyoung Kim, and Deog-Yeon Jo

Department of Internal Medicine, Chungnam National University Hospital, Daejeon, Korea

Received: August 16, 2016 Revised : October 26, 2016 Accepted: November 4, 2016

\section{Correspondence to}

Deog-Yeon Jo, M.D.

Division of Hematology and Oncology, Department of Internal Medicine, Chungnam National University Hospital, 282 Munhwa-ro, Jung-gu, Daejeon 35015, Korea

Tel: $+82-42-280-7162$

Fax: $+82-42-257-5753$

E-mail: deogyeon@cnu.ac.kr
Background/Aims: Renal complications related to BCR-ABL1-negative myeloproliferative neoplasms (MPNs) have not been examined fully in Asian populations. Methods: We analyzed estimated glomerular filtration rate (eGFR) and its changes with time retrospectively in patients with BCR-ABL1-negative MPN from 2005 to 2015 .

Results: The prevalence of chronic kidney disease (CKD) was $11 \%$ (6.6\% having stage 3 and $4.4 \%$ having stage 4). In a linear regression analysis of eGFR versus time (years), overall, patients showed increased eGFR ( $\left.\mathrm{mL} / \mathrm{min} / 1.73 \mathrm{~m}^{2}\right)$ by $0.51(95 \%$ confidence interval $[\mathrm{CI}],-0.30$ to $1.33 ; p=0.22$ ). Patients with polycythemia vera $(\mathrm{PV})$, and those treated with hydroxyurea, showed statistically significant increases in eGFR (1.59; 95\% CI, 0.28 to 2.90; $p=0.02$ in PV; and 1.55; 95\% CI, 0.56 to 2.54; $p=0.02$ in treatment with hydroxyurea). In total, 17 patients (20.5\%) showed rapid loss of eGFR ( $<-3 \mathrm{~mL} / \mathrm{min} / 1.73 \mathrm{~m}^{2}$ per year). This rapid loss in eGFR was associated with a higher incidence of kidney disease $(23.5 \%$ vs. $6.1 \%, p=0.05)$ and a higher percentage of patients with high neutrophil $\left(>7.0 \times 10^{9} / \mathrm{L}\right)$ and high monocyte $(>0.7$ $\left.\times 10^{9} / \mathrm{L}\right)$ counts $(76.5 \%$ vs. $50 \%, p=0.05 ; 52.9 \%$ vs. $28.8 \%, p=0.06$, respectively). More patients had high serum lactate dehydrogenase (> $500 \mathrm{U} / \mathrm{L})$ levels $(52.9 \%$ vs. $25.8 \%, p=0.03)$ at diagnosis.

Conclusions: CKD is prevalent in patients with BCR-ABL1-negative MPN. Active cytoreductive therapy has the potential to improve kidney function in BCR-ABL1-negative MPN.

Keywords: BCR-ABL1-negative myeloproliferative neoplasm; Renal insufficiency, chronic; Cytoreductive therapy; Chronic inflammation

\section{INTRODUCTION}

BCR-ABL1-negative myeloproliferative neoplasm (MPN) is an operational subcategory of MPN that includes polycythemia vera (PV), essential thrombocythemia (ET), primary myelofibrosis (PMF), and prefibrotic PMF, according to the World Health Organization (WHO) clas- sification system for hematopoietic tumors [1]. These disorders are characterized by stem cell-derived clonal myeloproliferation with mutually exclusive Janus kinase 2 (JAK2), calreticulin (CALR), or myeloproliferative leukemia virus oncogene (MPL) mutations $[2,3]$.

Major complications of MPN include thrombosis, microcirculatory disturbances, and bleeding [4]. In ad- 
dition to these well-known complications, some small case studies have suggested that BCR-ABL1-negative MPN is related to kidney problems, such as glomerulonephritis and nephrotic syndrome [5-11]. It has also been reported that histological findings, including segmental sclerosis and chronic thrombotic microangiopathy, were seen in most patients with BCR-ABL1-negative MPN [12]. Additionally, persistent renal dysfunction and progression to end-stage renal disease were not uncommon in these patients [12]. Recently, it has been reported that patients with Philadelphia-negative MPN had a high incidence $(29 \%)$ of chronic kidney disease (CKD) at diagnosis, which was assumed to be due primarily to chronic inflammation, related to the elevated cell counts [13].

Information on the prevalence of CKD and its clinical implications in patients with BCR-ABL1-negative MPN is quite limited, particularly in Asian populations. In the present study, we studied the prevalence of CKD and progression patterns of kidney function in patients with BCR-ABL1-negative MPN in a Korean population.

\section{METHODS}

\section{Study design}

Patients diagnosed with MPN, based on bone marrow studies at Chungnam National University Hospital between 2005 and 2015, were enrolled. This study was approved by the Institutional Review Board of Chungnam National University Hospital (2016-08-028).

Diagnostic criteria for MPN were based on the 2008 revised WHO criteria for MPN [1]. For patients diagnosed before 2008, the 2001 WHO criteria were used [14]. Patients were given a diagnosis of ET, PV, or PMF. For precise estimation of the patients' renal function, only stable patients with two creatinine values at baseline (time of diagnosis) and at least two creatinine samplings in the following years were included. The mean values of two creatinine measurements were used for estimated glomerular filtration rate (eGFR). In the linear regression analysis for estimating annual change of eGFR, only patients with follow-up periods of $>3$ years were included.

From patient records, two annual measurements of creatinine were extracted from the time of diagnosis until November 2015. Neutrophil counts, monocyte counts, and serum lactate dehydrogenase (LDH) levels at diagnosis were obtained. Monocyte and neutrophil counts were quantified (as $10^{9}$ cells/L) by automatic blood differential counting. The normal reference ranges for monocyte and neutrophil counts were 0.2 to $0.7 \times$ $10^{9}$ cells/L and 2.0 to $7.0 \times 10^{9}$ cells/L, respectively. The normal LDH reference range was 200 to 450 IU/L. Additionally, data on age, gender, smoking, JAK2 mutation status, comorbidities, medicine use, and conversion to myelodysplastic syndrome, acute myeloid leukemia, or secondary myelofibrosis were collected. Kidney function was evaluated using eGFR $\left(\mathrm{mL} / \mathrm{min} / 1.73 \mathrm{~m}^{2}\right)$, calculated based on the Modification of Diet in Renal Disease (MDRD) formula:

$$
\text { eGFR }=175 \times \text { [standardized serum creatinine }(\mathrm{mg} / \mathrm{dL})]^{-}
$$$$
1.154 \times[\text { age }(\text { years })]^{-0.203} \times[0.742 \text { if female }] \times[1.212 \text { if Afri- }
$$
can-American]

as recommended by the National Kidney Foundation Guidelines [15]. All patients were Korean; therefore, data were calculated as a non-black ethnic group.

\section{Definition of chronic kidney disease}

According to the National Kidney Foundation's Kidney Disease Outcome and Quality Initiative (KDOQI) guidelines, CKD is defined as kidney damage or eGFR $<60$ $\mathrm{mL} / \mathrm{min} / 1.73 \mathrm{~m}^{2}$ for at least 3 months. CKD is classified into five stages. CKD stages 1 and 2 are defined by evidence of kidney damage (proteinuria, hematuria, abnormal imaging, or biopsy) and eGFR > 90 and 60 to $89 \mathrm{~mL} / \mathrm{min} / 1.73 \mathrm{~m}^{2}$, respectively. CKD stages 3 to 5 are defined based solely on eGFR: stages 3,4 , and 5 are characterized by eGFRs in the ranges of 30 to 59,15 to 29 , and $<15 \mathrm{~mL} / \mathrm{min} / 1.73 \mathrm{~m}^{2}$, respectively [16].

\section{Data analysis}

Descriptive data are presented as means \pm standard deviation(SD), medians and ranges, or percentages, and were analyzed using Student $t$ test or chi-square tests (Fisher exact test). Kidney function in the cohort was evaluated at diagnosis as the mean of two measurements of eGFR in each patient at baseline. To evaluate annual change in eGFR, a linear regression analysis of eGFR versus time was made for the whole cohort and for each diagnostic group. Additionally, a regression of eGFR versus time was performed for a subgroup of patients treated with hydroxyurea (HU), and for a subgroup who were treated 
other than with HU (e.g., anagleride, phlebotomy). Regression analysis was also performed in each patient to obtain a patient-based estimate of the annual change in eGFR. SPSS version 20 (IBM Co., Armonk, NY, USA) was used to perform the analyses. A $p<0.05$ was considered to indicate statistical significance.

\section{RESULTS}

\section{Baseline characteristics and comorbidities}

In total, 136 patients with a median age of 62 years (range, 18 to 88) were enrolled: 72 ET patients, 46 PV patients, and $18 \mathrm{PMF}$ patients. At diagnosis, median eGFRs $\left(\mathrm{mL} / \mathrm{min} / 1.73 \mathrm{~m}^{2}\right)$ did not differ significantly between the diagnostic groups (81.4 [range, 34.6 to 129.5] in ET; 83.2 [range, 35.3 to 126.1] in PV; and 89.3 [range, 61.7 to 118.6] in PMF; $p=0.58$ ) (Table 1). Female patients accounted for $36.8 \%$ of cases. JAK2 mutation positivity was $52.8 \%$, 82.6\%, and 88.9\% in ET, PV, and PMF, respectively. Neutrophil counts at diagnosis were higher in the PV group than the other groups $(8.5 \pm 7.6$ vs. $10.8 \pm 6.3$ vs. $6.4 \pm 3.8$, $p=0.05)$. However, the monocyte count did not differ significantly between diagnostic groups $(0.7 \pm 0.5 \mathrm{vs} .0 .7$ \pm 0.5 vs. $0.6 \pm 0.5, p=0.49$ ). The LDH level was much higher in the PMF group than in the other groups (540 \pm 200 vs. $565 \pm 199$ vs. $1,160 \pm 587, p<0.01)$. Of the 136 patients, $83(61 \%)$ received HU treatment and 39 of the 46 PV patients $(84.8 \%)$ underwent phlebotomies. Comorbidities other than smoking history and kidney disease were not significantly different between the groups. The incidence of kidney disease, defined as massive proteinuria (>3 g/day) or glomerulonephritis, was $8.8 \%$. Patients with PV had a much higher incidence of kidney disease than patients in the other groups (5.6\% vs. $17.4 \%$ vs. $0 \%$, $p=0.04)$. In total, 59 patients $(43.4 \%)$ had urinary abnormalities at the time of diagnosis (Table 2). Two patients were diagnosed with membranous glomerulonephritis and one patient had focal segmental glomerulosclerosis.

\section{Prevalence of chronic kidney disease}

In total, 15 patients (11\%) had CKD, defined as eGFR $<60 \mathrm{~mL} / \mathrm{min} / 1.73 \mathrm{~m}^{2}$, at the time of diagnosis; nine (6.6\%) were in CKD stage 3 (eGFR, 30 to $59 \mathrm{~mL} / \mathrm{min} / 1.73 \mathrm{~m}^{2}$ ) and six (4.4\%) were in CKD stage 4 (eGFR, 15 to $29 \mathrm{~mL} / \mathrm{min} /$ $1.73 \mathrm{~m}^{2}$ ). The prevalence of CKD was higher in patients with ET than in the other groups $(16.5 \%, 6.5 \%$, and $\% \%$ in ET, PV, and PMF, respectively). The frequencies of CKD at diagnosis were $7.1 \%, 6.9 \%, 2.6 \%$, and $24.4 \%$ in patients $<49,50$ to 59,60 to 69 , and $>70$ years of age, respectively (Table 3).

\section{Progression patterns of kidney function}

A linear regression of eGFR versus time was performed to evaluate and quantify the progression of kidney function. For this analysis, 53 patients whose follow-up periods were $<3$ years were excluded. Fig. 1 shows regression lines for eGFR versus time according to diagnostic group (Fig. 1A) and HU treatment (Fig. 1B). The regression coefficients of the lines in Fig. 1 indicate the estimated annual change in eGFR (Table 4). The trend of the whole cohort showed an annual change of eGFR of $0.51 \mathrm{~mL} / \mathrm{min} / 1.73 \mathrm{~m}^{2}$ (95\% confidence interval [CI], -0.30 to 1.33). Patients with PV, and those treated with hydroxyurea, showed statistically significant increases in eGFR: $1.59 \mathrm{~mL} / \mathrm{min} / 1.73 \mathrm{~m}^{2}$ (95\% CI, 0.28 to $2.90 ; p=0.02$ ) and $1.55 \mathrm{~mL} / \mathrm{min} / 1.73 \mathrm{~m}^{2}$ (95\% CI, 0.56 to $2.54 ; p=0.02$ ), respectively. Additionally, 45 patients (54.2\%) showed improvements in kidney function (annual change in eGFR > $0 \mathrm{~mL} / \mathrm{min} / 1.73 \mathrm{~m}^{2}$ ) with time. More than half of these patients (56.5\%) received HU treatment. Regression analysis in each patient showed that 17 (20.5\%) experienced a rapid loss in kidney function (annual change of eGFR $<-3 \mathrm{~mL} / \mathrm{min} / 1.73 \mathrm{~m}^{2}$ ) during the study (Table 5). Comorbidities, except for kidney disease, did not differ significantly between the groups. Rapid loss of eGFR was associated with a higher incidence of kidney disease (23.5\% vs. $6.1 \%, p=0.05)$ and a higher percentage of patients having high monocyte $\left(>0.7 \times 10^{9}\right)$ and neutrophil $\left(>7.0 \times 10^{9}\right)$ counts $(52.9 \%$ vs. $28.8 \%, p=0.06 ; 76.5 \%$ vs. $50 \%, p=0.05)$. More patients had high LDH (> 500 U/L) levels ( $52.9 \%$ vs. $25.8 \%, p=0.03)$ at diagnosis.

\section{DISCUSSION}

In this single-center retrospective study, the prevalence of CKD in patients with BCR-ABL1-negative MPN was $11 \%$, with $6.6 \%$ having stage 3 , and $4.4 \%$ having stage 4 , CKD. According to the Korea Centers for Disease Control and Prevention, the prevalence of CKD in the Korean general population was $4.1 \%$ in 2013 [17]. Thus, the 
Table 1. Patient characteristics and comorbidities $(n=136)$

\begin{tabular}{|c|c|c|c|c|c|}
\hline Characteristic & $\mathrm{ET}(\mathrm{n}=72)$ & $\mathrm{PV}(\mathrm{n}=46)$ & $\operatorname{PMF}(\mathrm{n}=18)$ & $\operatorname{Total}(\mathrm{n}=136)$ & $p$ value \\
\hline Age, yr & $\begin{array}{c}64 \cdot 5 \\
(18-88)\end{array}$ & $\begin{array}{c}58.5 \\
(23-86)\end{array}$ & $\begin{array}{c}64 \\
(40-86)\end{array}$ & $\begin{array}{c}62 \\
(18-88)\end{array}$ & 0.23 \\
\hline Total years in cohort, yr & 304 & 224 & 45 & 573 & \\
\hline Female sex & $32(44 \cdot 4)$ & $12(26.1)$ & $6(33 \cdot 3)$ & $50(36.8)$ & 0.12 \\
\hline Palpable splenomegaly & $23(31.9)$ & $29(63)$ & $16(88.9)$ & $68(50)$ & $<0.01$ \\
\hline JAK2 mutation & $38(52.8)$ & $38(82.6)$ & $16(88.9)$ & $92(67.6)$ & $<0.01$ \\
\hline WBC, $10^{9} / \mathrm{L}$ & $12.2 \pm 8.3$ & $14.2 \pm 7.4$ & $10.3 \pm 6.2$ & $12.6 \pm 7.8$ & 0.17 \\
\hline Hemoglobin, g/dL & $13.3 \pm 2.2$ & $19.5 \pm 1.7$ & $10.8 \pm 2.8$ & $15.1 \pm 3.9$ & $<0.01$ \\
\hline Platelet, $10^{9} / \mathrm{L}$ & $904 \pm 349$ & $392 \pm 182$ & $381 \pm 344$ & $661 \pm 396$ & $<0.01$ \\
\hline Neutrophil, 109/L & $8.5 \pm 7.6$ & $10.8 \pm 6.3$ & $6.4 \pm 3.8$ & $9.0 \pm 6.9$ & 0.05 \\
\hline Monocyte, $10^{9} / \mathrm{L}$ & $0.7 \pm 0.5$ & $0.7 \pm 0.5$ & $0.6 \pm 0.5$ & $0.7 \pm 0.5$ & 0.49 \\
\hline LDH, U/L & $540 \pm 200$ & $565 \pm 199$ & $1160 \pm 587$ & $622 \pm 336$ & $<0.01$ \\
\hline $\mathrm{eGFR}, \mathrm{mL} / \mathrm{min} / 1.73 \mathrm{~m}^{2}$ & $\begin{array}{c}81.4 \\
(34.6-129.5)\end{array}$ & $\begin{array}{c}83.2 \\
(35 \cdot 3-126.1)\end{array}$ & $\begin{array}{c}89.3 \\
(61.7-118.6)\end{array}$ & $\begin{array}{c}82.1 \\
(34.6-129.5)\end{array}$ & 0.58 \\
\hline \multicolumn{6}{|l|}{ Treatment } \\
\hline Hydroxyurea & $46(63.9)$ & $30(65.2)$ & $7(38.9)$ & $83(61)$ & 0.12 \\
\hline Anagleride & $17(23.6)$ & $2(4 \cdot 3)$ & o & $19(14)$ & $<0.01$ \\
\hline Phlebotomy & 0 & $39(84.8)$ & 0 & $39(28.7)$ & $<0.01$ \\
\hline \multicolumn{6}{|l|}{ Comorbidities } \\
\hline Hypertension & $32(44 \cdot 4)$ & $22(47.8)$ & $5(27.8)$ & $59(43 \cdot 3)$ & 0.34 \\
\hline Diabetes mellitus & $14(19 \cdot 4)$ & $8(17 \cdot 4)$ & $3(16.7)$ & $25(18.4)$ & 0.95 \\
\hline Smokers/prior smokers & $16(22.2)$ & $28(60.9)$ & $3(16.7)$ & $47(34.6)$ & $<0.01$ \\
\hline $\mathrm{IHD}^{\mathrm{a}}$ & $8(11.1)$ & $4(8.7)$ & $1(5.6)$ & $13(9.6)$ & 0.39 \\
\hline Stroke ${ }^{b}$ & $21(29.2)$ & $7(15 \cdot 2)$ & $2(11.1)$ & $30(22.1)$ & 0.08 \\
\hline Other atherosclerotic disease $\mathrm{c}^{\mathrm{c}}$ & $5(6.9)$ & $2(4 \cdot 3)$ & o & $7(5.1)$ & 0.64 \\
\hline DVT/PTE & $1(1.4)$ & $3(6.5)$ & 0 & $4(2.9)$ & 0.35 \\
\hline Kidney disease $^{\mathrm{d}}$ & $4(5 \cdot 6)$ & $8(17 \cdot 4)$ & o & $12(8.8)$ & 0.04 \\
\hline Cancers before diagnosis of MPN & $4(5 \cdot 6)$ & $3(6.5)$ & $2(11.1)$ & $9(6.6)$ & 0.71 \\
\hline Cancers after diagnosis of MPN & $3(4.2)$ & $4(8.7)$ & o & $7(5.1)$ & 0.47 \\
\hline Transformation & & & & & $<0.01$ \\
\hline Myelofibrosis & $4(5 \cdot 6)$ & $1(2.2)$ & o & $5(3 \cdot 7)$ & \\
\hline MDS & 0 & $1(2.2)$ & 0 & $1(0.7)$ & \\
\hline $\mathrm{AML}$ & $1(1.4)$ & 0 & $4(22.2)$ & $5(3.7)$ & \\
\hline
\end{tabular}

Values are presented as median (range), number (\%), or mean \pm SD.

ET, essential thrombocythemia; PV, polycythemia vera; PMF, primary myelofibrosis; WBC, white blood cell; LDH, lactate dehydrogenase; eGFR, estimated glomerular filtration rate; IHD, ischemic heart disease; DVT, deep-vein thrombosis, PTE, pulmonary thromboembolism; MPN, myeloproliferative neoplasm; MDS, myelodysplastic syndrome; AML, acute myeloid leukemia.

${ }^{a}$ Angina pectoris including myocardial infarction.

${ }^{\mathrm{b}}$ Cerebral hemorrhage and cerebral infarction.

${ }^{\mathrm{c}}$ Arterial aneurism and thrombosis, intermittent claudication.

${ }^{\mathrm{d}}$ Proteinuria (> $3 \mathrm{~g} /$ day) or glomerulonephritis. 
Table 2. Kidney disease and urinary abnormalities $(n=136)$

\begin{tabular}{|c|c|c|c|c|}
\hline Variable & $\mathrm{ET}(\mathrm{n}=72)$ & $\mathrm{PV}(\mathrm{n}=46)$ & $\operatorname{PMF}(\mathrm{n}=18)$ & $\operatorname{Total}(n=136)$ \\
\hline None & $47(65 \cdot 3)$ & $20(43.5)$ & $10(55.6)$ & $77(56.6)$ \\
\hline Microscopic hematuria & $8(11.1)$ & $5(10.9)$ & $2(11.1)$ & $15(11.0)$ \\
\hline Mild-to-moderate proteinuria & $13(18.0)$ & $12(26.1)$ & $6(33 \cdot 3)$ & $31(22.8)$ \\
\hline Massive proteinuria (> $3 \mathrm{~g} /$ day) & $4(5.6)$ & $6(13.0)$ & 0 & $10(7.4)$ \\
\hline Glomerulonephritis & $\mathrm{O}$ & $3(6.5)$ & 0 & $3(2.2)$ \\
\hline
\end{tabular}

Values are presented as number (\%).

ET, essential thrombocythemia; PV, polycythemia vera; PMF, primary myelofibrosis.

Table 3. Estimated glomerular filtration rate at diagnosis $(n=136)$

\begin{tabular}{|c|c|c|c|c|c|}
\hline $\mathrm{eGFR}, \mathrm{mL} / \mathrm{min} / 1.73 \mathrm{~m}^{2}$ & $\mathrm{ET}(\mathrm{n}=72)$ & $\mathrm{PV}(\mathrm{n}=46)$ & $\operatorname{PMF}(\mathrm{n}=18)$ & Total $(n=136)$ & Total cumulative, $\%$ \\
\hline $15-29^{a}$ & o & o & o & o & o \\
\hline $30-44^{b}$ & $4(5 \cdot 6)$ & $2(4 \cdot 3)$ & o & $6(4.4)$ & $4 \cdot 4$ \\
\hline $45-59^{b}$ & $8(11.1)$ & $1(2.2)$ & o & $9(6.6)$ & 11.0 \\
\hline $60-74$ & $15(20.8)$ & $15(32.6)$ & $6(33.3)$ & $36(26.5)$ & $37 \cdot 5$ \\
\hline $75-89$ & $20(27.8)$ & $11(23.9)$ & $3(16.7)$ & $34(25.0)$ & 62.5 \\
\hline$\geq 90$ & $25(34.7)$ & $17(37.0)$ & $9(50.0)$ & $51(37.5)$ & 100 \\
\hline
\end{tabular}

Values are presented as number (\%).

eGFR, estimated glomerular filtration rate; ET, essential thrombocythemia; PV, polycythemia vera; PMF, primary myelofibrosis. ${ }^{a}$ Level of eGFR qualifies as chronic kidney disease (CKD) stage 4.

${ }^{\mathrm{b}}$ Level of eGFR qualifies as CKD stage 3 .
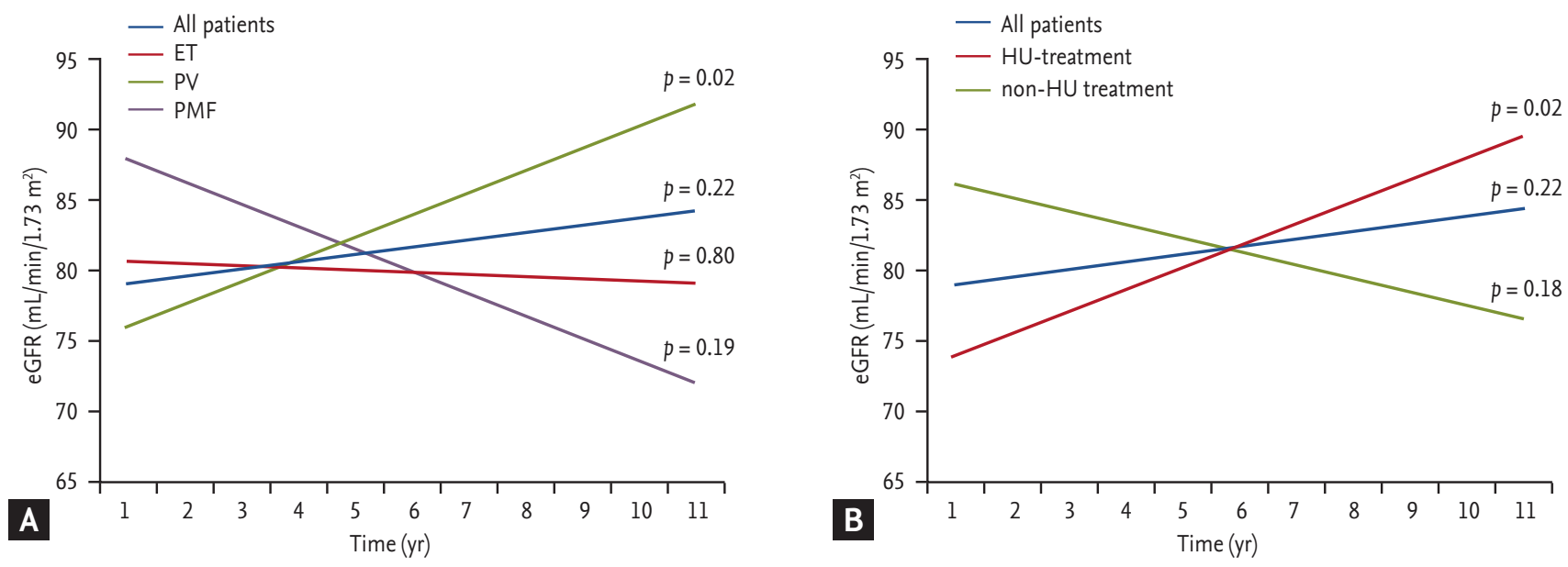

Figure 1. Linear regression lines of estimated glomerular filtration rate (eGFR) (mL/min/1.73 $\mathrm{m}^{2}$ ) versus time (years) in all patients, diagnostic groups (A), and according to hydroxyurea treatment (B). Coefficients for change of eGFR per year (slope) and estimated baseline mean eGFR (intercepts) are presented (Table 4). ET, essential thrombocythemia; PV, polycythemia vera; PMF, primary myelofibrosis; HU, hydroxyurea.

prevalence of CKD in patients with BCR-ABL1-negative MPN was much higher than that in the general population. These results are consistent with a recent Danish study on CKD in patients with Philadelphia-negative MPN, which reported that the prevalence of CKD in such patients was $29 \%$ (27\% with CKD stage 3, $2 \%$ with 
Table 4. Linear regression ${ }^{\mathrm{a}}$ in the different groups $(n=83)$

\begin{tabular}{|c|c|c|c|c|}
\hline \multirow{2}{*}{ Variable } & \multicolumn{2}{|l|}{ Baseline } & \multicolumn{2}{|l|}{ Regression coefficient } \\
\hline & Mean eGFR (95\% CI) & $p$ value & Change in eGFR per year ( $95 \% \mathrm{CI})$ & $p$ value \\
\hline All patients & $80.2(76.0$ to 84.4$)$ & & $0.51(-0.30$ to 1.33$)$ & \\
\hline Groups & & 0.79 & & 0.06 \\
\hline ET & $79.5(73.8$ to 85.3$)$ & & $-0.15(-1.28$ to 0.99$)$ & \\
\hline PV & $80.2(73.0$ to 87.4$)$ & & $1.59(0.28$ to 2.90$)$ & \\
\hline $\mathrm{PMF}$ & $85.7(67.1$ to 104.3$)$ & & $-1.60(-4.03$ to 0.83$)$ & \\
\hline Hydroxyurea-treated & & 0.03 & & 0.33 \\
\hline Yes & $76.0(70.4$ to 81.5$)$ & & $1.55(0.56$ to 2.54$)$ & \\
\hline No & $85.4(79.1$ to 91.7$)$ & & $-0.95(-2.34$ to 0.43$)$ & \\
\hline
\end{tabular}

eGFR, estimated glomerular filtration rate; CI, confidence interval; ET, essential thrombocythemia; PV, polycythemia vera; PMF, primary myelofibrosis.

${ }^{a}$ Linear regression of eGFR ( $\mathrm{mL} / \mathrm{min} / 1.73 \mathrm{~m}^{2}$ ) versus time (years) in all patients, diagnostic groups, and according to hydroxyurea treatment.

Table 5. Patient characteristics according to annual change in eGFR $(n=83)$

\begin{tabular}{|c|c|c|c|}
\hline \multirow[b]{2}{*}{ Characteristic } & \multicolumn{3}{|c|}{ Annual change in eGFR } \\
\hline & $\begin{array}{l}\text { Rapid eGFR loss }(<-3) \\
\qquad(\mathrm{n}=17)\end{array}$ & $\begin{array}{l}\text { Mild decline or increase }(>-3) \\
\qquad(\mathrm{n}=66)\end{array}$ & $p$ value \\
\hline Age, yr & $64.1 \pm 10.4$ & $57.0 \pm 15.1$ & 0.07 \\
\hline Female sex & $6(35 \cdot 3)$ & $27(40.9)$ & 0.67 \\
\hline Hypertension & $8(47 \cdot 1)$ & $25(37.9)$ & 0.49 \\
\hline Diabetes mellitus & $5(29 \cdot 4)$ & $9(13.6)$ & 0.15 \\
\hline Smokers or prior smokers & $7(41.2)$ & $20(30.3)$ & 0.39 \\
\hline Stroke ${ }^{a}$ & $3(17.6)$ & $13(19.7)$ & 1.00 \\
\hline Ischemic heart disease ${ }^{b}$ & $3(17.6)$ & $6(9.1)$ & 0.38 \\
\hline Other atherosclerotic disease ${ }^{c}$ & $1(5 \cdot 9)$ & $4(6.1)$ & 1.00 \\
\hline Kidney disease $^{\mathrm{d}}$ & $4(23.5)$ & $4(6.1)$ & 0.05 \\
\hline Diagnosis & & & 0.09 \\
\hline $\mathrm{ET}$ & $9(52.9)$ & $37(56.1)$ & \\
\hline PV & $5(29 \cdot 4)$ & $27(40.9)$ & \\
\hline PMF & $3(17.6)$ & $2(3.0)$ & \\
\hline \multicolumn{4}{|l|}{ Laboratory findings at diagnosis } \\
\hline Neutrophil > $7.0 \times 10^{9} / \mathrm{L}$ & $13(76.5)$ & $33(50)$ & 0.05 \\
\hline Monocyte $>0.7 \times 10^{9} / \mathrm{L}$ & $9(52.9)$ & $19(28.8)$ & 0.06 \\
\hline $\mathrm{LDH}>500 \mathrm{U} / \mathrm{L}$ & $9(52.9)$ & $17(25.8)$ & 0.03 \\
\hline $\mathrm{eGFR}, \mathrm{mL} / \mathrm{min} / 1.73 \mathrm{~m}^{2}$ & $80.5 \pm 20.4$ & $80.1 \pm 19.1$ & 0.94 \\
\hline Hydroxyurea-treated & $7(41.2)$ & $39(59.1)$ & 0.19 \\
\hline
\end{tabular}

Values are presented as mean \pm SD or number (\%).

eGFR, estimated glomerular filtration rate; ET, essential thrombocythemia; PV, polycythemia vera; PMF, primary myelofibrosis; LDH, lactate dehydrogenase.

${ }^{\mathrm{a}}$ Cerebral hemorrhage and cerebral infarction.

${ }^{\mathrm{b}}$ Angina pectoris including myocardial infarction.

${ }^{\mathrm{c}}$ Arterial aneurism and thrombosis, intermittent claudication.

${ }^{\mathrm{d}}$ Proteinuria (> $3 \mathrm{~g} /$ day) or glomerulonephritis. 
CKD stage 4) [13]. The frequency of CKD in patients with $B C R-A B L 1$-negative MPN tended to be higher than in each age group of the general population, except for the 60 to 69 years of age group ( $7.1 \%$ vs. $1.3 \%, 6.9 \%$ vs. $2.9 \%$, $2.6 \%$ vs. $7.9 \%$, and $24.4 \%$ vs. $20.4 \%$ in patients of $<49,50$ to 59,60 to 69 , and $>70$ years of age, respectively). These results suggest that MPN itself might have a deteriorating impact on kidney function even before the time of diagnosis.

In terms of progression patterns of kidney function, overall, patients showed an increase in eGFR by 0.51 $\mathrm{mL} / \mathrm{min} / 1.73 \mathrm{~m}^{2}$. In particular, patients with $\mathrm{PV}$, and those treated with hydroxyurea, showed a statistically significant increases in eGFR $\left(1.59 \mathrm{~mL} / \mathrm{min} / 1.73 \mathrm{~m}^{2}\right.$, $p=0.02 ; 1.55 \mathrm{~mL} / \mathrm{min} / 1.73 \mathrm{~m}^{2}, p=0.02$, respectively). In total, 45 patients $(54.2 \%)$ showed improvements in kidney function during the study. This improvement can be attributed to various factors. First, patients with PV have high hematocrits and hyperviscosity, which might lead to a high incidence of hypertension. Additionally, hyperviscosity causes impaired microvascular circulation. Second, elevated leukocytes and platelet counts are known to cause atherothrombosis and inflammatory immune responses by "platelet-leukocyte interactions" [18]. These phenomena may be attenuated by cytoreductive therapy, such as treatment with HU or phlebotomy and low-dose aspirin. Third, hyperuricemia is known to increased blood pressure and decrease GFR by inducing endothelial dysfunction [19-21]. Thus, allopurinol may be helpful in improving kidney function by reducing uric acid levels. However, a considerable number of patients (20.5\%) showed rapid eGFR loss during the study. More patients with rapid loss of eGFR were found to have high neutrophil $\left(>7.0 \times 10^{9} / \mathrm{L}\right)$ and monocyte $(>0.7$ $\left.\times 10^{9} / \mathrm{L}\right)$ counts and high $\mathrm{LDH}(>500 \mathrm{IU} / \mathrm{L})$ levels at diagnosis. In a recent study by Christensen et al. [13], eGFR and log monocyte count showed a significant negative correlation in all Philadelphia-negative MPN patients $(r$ $=-0.11, p<0.01)$. There are several lines of evidence on chronic inflammatory effects of elevated cell counts related to MPN. Skov et al. [22] reported that MPN may be closely associated with chronic inflammatory disorders because molecular profiling of peripheral blood cells demonstrated aberrant expression of genes involved in inflammatory responses, mainly in granulocytes or $\mathrm{CD}_{34} 4^{+}$cells. Additionally, several studies on the patho- genesis of PMF reported that myelofibrosis could be a reactive process, mediated by megakaryocyte-derived overproduction of growth factors, such as platelet-derived growth factor and transforming growth factor $\beta$ $[23,24]$. Taken together, chronic inflammation related to MPN may be closely associated with the progression of kidney function.

Our study had several limitations. The difference in the prevalence of CKD between Danish study and our study (29\% vs. $11 \%)$ may be related with following factors [13]. First, this was a retrospective uncontrolled study, so there may be unavoidable confounding factors such as selection bias. Second, creatinine level may not represent the eGFR precisely, because it is influenced by various factors including body composition (e.g., muscle mass) and medications. Additionally, the MDRD equation is known to have decreased reliability and accuracy in extremes of GFR [25]. Thus, a considerable number of elderly patients may have overestimated eGFRs (58\% of the patients were more than 60 years old in our study). Third, the large differences in sample size among the groups limits the conclusions. MPN is a relatively rare disorder. Thus, it will not be easy to include a sufficient number of patients from a single institution. However, this retrospective study is the first report of MPN-related kidney dysfunction in an Asian population. Hopefully, further well-designed prospective studies on renal complications in patients with MPN will be performed in the future.

In conclusion, patients with BCR-ABL1-negative MPN have a high incidence of CKD. The renal impairment tends to be related to elevated blood cell counts. Thus, we suggest that active cytoreductive therapy and close renal function monitoring could improve renal function or prevent further deterioration in these patients.

\section{KEY MESSAGE}

1. Chronic kidney disease is prevalent in patients with BCR-ABL1-negative myeloproliferative neoplasm.

2. Cytoreductive therapy has the potential to improve kidney function by reducing chronic inflammation and improving the microcirculation. 


\section{Conflict of interest}

No potential conflict of interest relevant to this article was reported.

\section{REFERENCES}

1. Vardiman JW, Thiele J, Arber DA, et al. The 2008 revision of the World Health Organization (WHO) classification of myeloid neoplasms and acute leukemia: rationale and important changes. Blood 2009;114:937-951.

2. Tefferi A. Novel mutations and their functional and clinical relevance in myeloproliferative neoplasms: JAK2, MPL, TET2, ASXL1, CBL, IDH and IKZF1. Leukemia 2010;24:1128-1138.

3. Tefferi A, Thiele J, Vannucchi AM, Barbui T. An overview on CALR and $\mathrm{CSF}_{3} \mathrm{R}$ mutations and a proposal for revision of WHO diagnostic criteria for myeloproliferative neoplasms. Leukemia 2014;28:1407-1413.

4. Elliott MA, Tefferi A. Thrombosis and haemorrhage in polycythaemia vera and essential thrombocythaemia. Br J Haematol 2005;128:275-290.

5. Oymak O, Oymak FS, Patiroglu T, et al. Polycythemia vera presenting with rapidly progressive glomerulonephritis and pyoderma gangrenosum. Nephron 2000;86:346-347.

6. Plomley RF, Sullivan JR, Whitworth JA, Kincaid-Smith PS, Fairley KF, Brown RW. Polycythemia vera and glomerulonephritis. Aust N Z J Med 1983;13:125-129.

7. Asaba K, Tojo A, Onozato ML, et al. Fibrillary glomerulonephritis associated with essential thrombocytosis. Clin Exp Nephrol 2003;7:296-300.

8. Kornblihtt LI, Vassalllu PS, Heller PG, Lago NR, Alvarez CL, Molinas FC. Primary myelofibrosis in a patient who developed primary biliary cirrhosis, autoimmune hemolytic anemia and fibrillary glomerulonephritis. Ann Hematol 2008;87:1019-1020.

9. Jung YJ, Kim B, Moon KH, et al. Concurrent IgA nephropathy and minimal change disease in a patient with polycythemia vera: a case report. Korean J Nephrol 2008;27:733-737.

10. Han DH, Cho S, Kim SR, et al. A case of minimal change nephrotic syndrome with polycythemia vera. Korean J Med 2007;73:438-442.

11. Park MO, Baek HJ, Song SY. A case of polycythemia vera combined with focal segmental glomerulosclerosis. Korean J Hematol 2007;42:58-61.
12. Said SM, Leung N, Sethi S, et al. Myeloproliferative neoplasms cause glomerulopathy. Kidney Int 2011;80:753-759.

13. Christensen AS, Moller JB, Hasselbalch HC. Chronic kidney disease in patients with the Philadelphia-negative chronic myeloproliferative neoplasms. Leuk Res 2014;38:490-495.

14. Kleihues P, Sobin LH. World Health Organization classification of tumors. Cancer 2000;88:2887.

15. Jones GR, Lim EM. The National Kidney Foundation guideline on estimation of the glomerular filtration rate. Clin Biochem Rev 2003;24:95-98.

16. Levey AS, Coresh J, Balk E, et al. National Kidney Foundation practice guidelines for chronic kidney disease: evaluation, classification, and stratification. Ann Intern Med 2003;139:137-147.

17. Lee HM, Oh KW. Prevalence of chronic kidney disease in Korea, 2013. Public Health Wkly Rep 2013;8:242-244.

18. Totani L, Evangelista V. Platelet-leukocyte interactions in cardiovascular disease and beyond. Arterioscler Thromb Vasc Biol 2010;30:2357-2361.

19. Kanbay M, Ozkara A, Selcoki Y, et al. Effect of treatment of hyperuricemia with allopurinol on blood pressure, creatinine clearence, and proteinuria in patients with normal renal functions. Int Urol Nephrol 2007;39:1227-1233.

20. Khosla UM, Zharikov S, Finch JL, et al. Hyperuricemia induces endothelial dysfunction. Kidney Int 2005;67:1739-1742.

21. Sanchez-Lozada LG, Tapia E, Santamaria J, et al. Mild hyperuricemia induces vasoconstriction and maintains glomerular hypertension in normal and remnant kidney rats. Kidney Int 2005;67:237-247.

22. Skov V, Larsen TS, Thomassen M, et al. Molecular profiling of peripheral blood cells from patients with polycythemia vera and related neoplasms: identification of deregulated genes of significance for inflammation and immune surveillance. Leuk Res 2012;36:1387-1392.

23. Martyre MC. TGF-beta and megakaryocytes in the pathogenesis of myelofibrosis in myeloproliferative disorders. Leuk Lymphoma 1995;20:39-44.

24. Martyre MC, Magdelenat H, Bryckaert MC, Laine-Bidron C, Calvo F. Increased intraplatelet levels of platelet-derived growth factor and transforming growth factor-beta in patients with myelofibrosis with myeloid metaplasia. Br J Haematol 1991;77:80-86.

25. Levey AS, Coresh J, Bolton K, et al. K/DOQI clinical practice guidelines for chronic kidney disease. Am J Kidney Dis 2002;39(2 suppl 1):S11-S12. 